\title{
Energy management as production input
}

\author{
G. Perillo \\ Department of Technology, Naples Parthenope University, Italy
}

\begin{abstract}
In the past, big companies considered offices and shops the main strategic asset of their portfolio. However, only companies with foresight, that have created and established an online presence, jumped ahead of the competition. Today, we are now verifying a similar distortion with regard to industrial energy consumption.

Traditionally, energy is seen as a cost, a bill to be paid and an expense to be controlled. Companies ready for the future, however, have gained a new perspective toward energy and are transforming their businesses, particularly those manufacturing, in order to capitalize on the real value of energy as a "raw material" and as a usable resource to grow and sustain their businesses in the future. All companies, big and small, will have to know exactly where to use this valuable resource and how to register it as a voice in the bill of materials (BOM) of production, in Gigajoule or BTUs per ton of product. The management of this information in real time enables you to administer the energy really careful, in order to sustain profitability.

Keywords: energy resources, automation and control, management.
\end{abstract}

\section{Introduction}

Under constant pressure to squeeze more out of their operating budgets, manufacturers often turn to their Operations teams to drive innovative improvements that lead to cost savings [1]. Known for constantly seeking savings in everything they do, Operations teams are constantly investigating ways to increase throughput, improve quality, reduce waste and optimize labour. Despite the success of these efforts, management continues to increase its expectations, demanding further reduction in operating expenses while maintaining - or even increasing - production. In the past, achieving these goals has been accomplished through a combination of equipment upgrades, Lean Six Sigma processes and other incremental improvements. Today, the low-hanging, 
expense-reduction fruit has long been picked. Continuing to beat the numbers will require the Operations team to take a new approach - one that considers the role of energy within the operations.

In the industrial sector, energy is one of the most elusive and difficult cost to manage, since its high price variability and supply volatility (fig. 1).

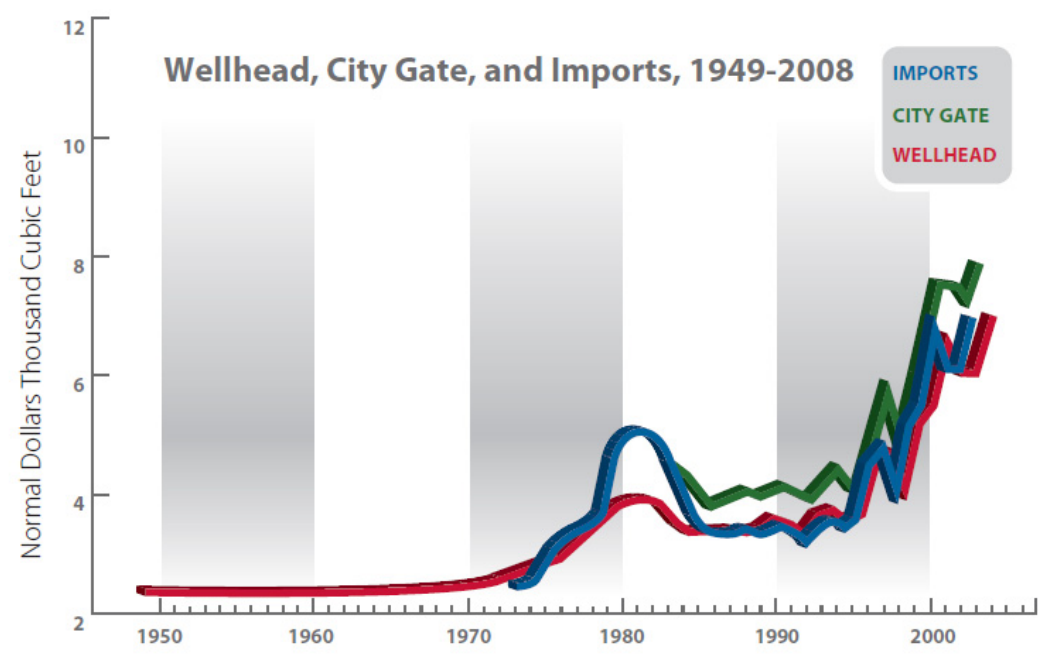

Figure 1: Gas prices natural variations: producer prices (Wellhead), distributors (City Gate), and imports (Import) per unit from 1949 to 2008 .

\section{The complexity of energy management}

Manufacturers around the world have put forth commendable efforts to reduce water, air, gas, electric and steam (WAGES) consumption. However, despite individual reduction efforts, WAGES resources have become one of the most elusive and hard-to-manage costs in manufacturing, with high levels of cost variability and supply volatility. Manufacturers face the very real possibility that water, gas, fuel oil or electricity may not be available when they need them [2].

For example, less than one percent of the world's water is available for human use; yet consumption is estimated to increase by 40 percent over the next 20 years. Meanwhile, world manufacturing energy consumption is projected to increase by 44 percent from 2006 to 2030, according to the U.S. Energy Information Administration. Yet, growth in electrical power generation will average just 1.1 percent per year from 2007 to 2035. These risks and uncertainties can wreak havoc on a company's operations, ability to deliver and their bottom line. By better understanding and managing WAGES resource consumption across the company, manufacturers can better defend themselves against these threats. 
Companies also are confronted with the challenge of maintaining brand equity and corporate reputation in the face of increased scrutiny from consumers and major retailers who distribute their products [3]. Large retailers such as WalMart have begun to judge suppliers based on "scorecards" that track products' environmental impact throughout the supply chain, illustrating to consumers a company's social responsibility. Consumers and stakeholders are using similar rating systems to pay closer attention to energy usage as they decide which products to buy. Furthermore, many organizations are participating in voluntary programs for greenhouse gas reporting and other sustainability initiatives, such as the Carbon Disclosure Project, which create internal imperatives for continuous improvement in energy usage in order to improve reported metrics. As a result, manufacturers must better manage the energy used in their production processes and prepare for the possibility of carbon labelling and other finite measurements of energy usage at the unit level.

There are also regulatory concerns to manage. The U.S. Congress and the Executive Branch have proposed several initiatives that will compel manufacturers to do a better job of managing energy. Potential changes to the Smart Grid, including access to expanded supply and the possibility of real-time pricing, add to the complexity [4].

And it's not just the U.S - at the end of 2006, the EU pledged to cut its annual consumption of primary energy 20 percent by 2020 . To help achieve this goal, it is working to mobilize decision makers to set minimum energy efficiency standards and rules on labelling for products, services and infrastructure. These directives require multisite manufacturers to optimize not only within a single facility but also across a global network of manufacturers and suppliers. Emissions legislation such as cap-and-trade only adds to the multitude of reasons to focus extensively on energy management; attentive organizations are asking themselves how they can use these challenges not only to comply, but also to position themselves for success.

\section{A paradigm for inside-out energy management}

The sheer size of the unrealized opportunity for improved efficiency is stunning. According to a recent report from McKinsey \& Company, Unlocking Energy Efficiency in the U.S. Economy, "The industrial sector offers 3,650 trillion enduse BTUs of NPV positive energy efficiency potential, equivalent to 18 percent of its forecast energy consumption in 2020." However, a significant number of industrial WAGES users remain unaware of the efficiency opportunities available to them. Fortunately, for the first time in industrial history, the automation, control, optimization and information solutions necessary to conquer the energy challenge are in place or readily available, and can be applied immediately to achieve measurable results [5].

The following describes an "inside-out" approach that enables manufacturers to use existing automation and power control investments to begin saving WAGES resources more effectively, and investing them more intelligently. 
Through a four-stage methodology, manufacturers can transform their practices and production to enable supply chain optimization and boost profitability.

This blueprint - or what Rockwell Automation refers to as an "Industrial Green Print" - for achieving WAGES optimization, helps manufacturers gain better control over how they use those resources, helping reduce the burden of utilities costs on profitability and lessen the risks associated with external factors affecting energy price and supply. The following pages will describe in detail each of these stages - "Awareness", "Efficiency", "Optimization" and "Aggregation".

\subsection{Stage one: industrial green print awareness}

At the first stage of the Industrial Green Print, companies conduct ongoing audits and assessments to identify a wide range of changes that can help reduce consumption. Leveraging existing automation systems, companies collect WAGES consumption data, which helps take a holistic view of energy for the organization and establish the scope of an energy savings effort. These efforts help companies define key metrics and put the appropriate resources in place. Recommendations may include low-investment modifications, such as shifting maintenance operations to non-peak times, or may be more involved, such as equipment programming changes. Evaluation and prioritization of capital improvement opportunities can also be included in the analyses.

Armed with a comprehensive assessment of current WAGES usage, manufacturers can set a facility consumption baseline. They also can monitor for variations or spikes that could cause damage to equipment inside the plant and cause power factor problems on the energy grid. Knowing these risks, manufacturers can better protect their equipment and avoid incurring penalty fees from the utility companies who will charge manufacturers for their efforts to correct power factor issues on the grid. In addition, companies can use trending and time-of-use information to set targets for improvements, which can lower WAGES costs and reduce greenhouse gas emissions [6].

The Awareness stage of the Industrial Green Print also simplifies compliance with ISO-50001, the forthcoming framework for industrial plants, commercial facilities and entire organizations to manage energy. According to the International Organization for Standardization (ISO), it is believed that the standard could influence up to 60 percent of the world's energy use. It will provide benchmarking, measuring, documenting and reporting best practices for WAGES efficiency improvements and their projected impact on reductions in greenhouse gas emissions.

\subsection{Stage two: industrial green print efficiency}

By leveraging the WAGES consumption data gathered in the Awareness stage, the Efficiency stage of the Industrial Green Print enables companies to make incremental and proactive behavioural, control and equipment improvements, such as forecasting, load aggregation and rate analysis exercises. At this stage, both corporate management personnel and plant management gain a clearer view 
of exactly how much of the company's overall energy use is consumed by the manufacturing process versus how much is consumed by operational functions such as data centres. Whereas businesses traditionally have allocated energy costs evenly across a facility regardless of actual consumption variances, micromonitoring allows them to track and project energy expenditures according to actual use throughout the facility.

More importantly, employees at the efficiency stage leverage a customizable reporting dashboard featuring weather-normalized predictive modelling, as well as worldwide key performance indicators and reports for comparison of multiple facilities. For example, a plant manager can use this insight to pinpoint variable WAGES costs on the plant floor, and consider ways to improve profitability. Manufacturers also can influence machine design practices to improve energy management such as specifying motors in different power ranges or attaching monitoring devices to assist with data collection.

This knowledge could also add a new dimension to commonly-used operational equipment effectiveness (OEE) equations which currently only take into account product quality, equipment uptime and production output rates. By gaining a clearer understanding of WAGES consumption at the plant floor level, manufacturers could modify the OEE calculations to include energy efficiency. Through this optimized asset utilization and WAGES procurement, companies can add dollars to the bottom line and enjoy an increased competitive edge.

\subsection{Stage three: industrial green print optimization}

The third stage of the Industrial Green Print allows manufacturers to optimize their plant floor assets by modelling production with WAGES resources as economic variables. All data sets gathered in stage two, including production metrics, regulatory reports, and behavioural and climate forecasts, are combined into a single automated solution that can identify, model, visualize and present control options. Production scheduling managers can then leverage production simulation software tools to input variables, such as peak and off-peak energy costs, raw material costs, labour and projected emissions. They also can pre-test "what-if" scenarios to see how production outputs and costs will change as a result of modifications [7].

Looking beyond individual production cycles, manufacturers also can forecast the full sequence of production scheduling to optimize overall production. For example, if the cost of natural gas increases, the control system might indicate to a manufacturer that they will save money by generating their own energy until the price comes down. Or it might determine that a different ratio of WAGES resources will be beneficial to cost, but damaging to emissions rates. All these considerations can be modelled and optimized automatically within this framework, using the control system already in place. As a result, manufacturers can optimize all production assets and forecast the most economical way to manufacture their products. 


\subsection{Stage four: industrial green print aggregation}

Armed with the optimized production information obtained in stage three, the Aggregation stage of the Industrial Green Print is where manufacturers project, in advance, how much energy will be required for similar loads or batches. Manufacturers can then include WAGES requirements in resource planning and scheduling decisions in the same way they consider the availability of raw materials or other inputs on the bill of materials.

Empirically tying WAGES consumption requirements to the bill of materials enables a plant manager or production scheduling manager to make proactive production decisions, and better manage energy investments in a way that will generate a greater return. For example, by knowing that certain batches require more natural resources, managers can move those batches outside peak windows.

This knowledge enables better overall business decisions as well. Knowing how much energy (and therefore additional cost) is required to manufacture a specific product, a product marketing professional may realize that specific product is not priced appropriately to generate a strong margin and can make adjustments accordingly.

At this stage, energy and its associated greenhouse gas emissions are no longer fixed allocations that are simply part of unavoidable overhead. Manufacturers who add WAGES resources to the bill of materials can actively manage it as an input to achieve higher profitability. In addition, this unit-level energy consumption information becomes valuable input to sustainability scorecards and other reporting mechanisms, allowing companies to better optimize their full supply chain to enhance their sustainability and energy programs.

For example, in the factory of the future, an ice cream manufacturer might wish to enhance their operations to select raw materials or shipping choices that will support an ideal "sustainability score." The company might choose a dairy based not only on the price of the milk, but also on the potential carbon or energy footprint of shipping the milk to the facility. Additionally, the transportation routes for the outbound product can be optimized to account for weather factors that might impact the energy needed to chill and store the product.

\section{Conclusions}

As WAGES costs and supplies continue to fluctuate and manufacturing consumption of energy resources comes under more scrutiny from consumers, businesses and governments, manufacturers will find that it is not only responsible, but also fiscally essential to their businesses to address WAGES management practices. Fortunately, the necessary combination of automation and information provides solutions that are available today to help manufacturers monitor, measure, model and control resources for optimal profits. Manufacturers who adopt a strategic approach to WAGES resource management are able to leverage their existing automation and power system investments to 
make more of natural resources, which helps lower production costs, optimize profits, and address economic and regulatory drivers.

The cost of purchasing the energy needed for production by an industrial facility is viewed as managed input and typically receives significant attention, while the use of that energy once it is inside the factory is often viewed as simply the cost of doing business. While this is not true in all industrial facilities, experience has shown that unless the facility actively manages energy use and has a documented plan for doing so, these facilities are significantly less energy efficient than they could be. Without performance indicators that relate energy consumption to production output, it is difficult to measure or document improvements in energy intensity.

\section{References}

[1] Training Course Description: RE0520: AUTOMAX Maintenance. Publication Number: GMST10-PP230B-EN-E, August 2012, Brand: AllenBradley.

[2] Certificate Program - ControlLogix - Maintainer Curriculum. Publication Number: GMST10-PP406G-EN-E, February 2016.

[3] International Cheese Producer Case Study. Publication Number: RSCS10AP004A-EN-P, August 2010. Brand: Rockwell Software.

[4] The Journal from Rockwell Automation Product Focus. Publication Number: 5058M-AR101A-EN-E, April 2010. Brand: Allen-Bradley.

[5] Course Description EM-105: Wiring. Publication Number: GMST10PP567A-EN-E, January 2014. Brand: Allen-Bradley.

[6] Solutions in Action: Taylor Products THP-5500. Publication Number: OEM-AP166A-EN-P, August 2011. Brand: Allen-Bradley.

[7] Local Field Service Flyer - Cleveland District. Publication Number: GMSCSP014A-EN-P, February 2014. Brand: Product Category. 